\footnotetext{
JURNAL CEMERLANG: Pengabdian pada Masyarakat

P-ISSN 2654-4741 / E-ISSN 2655-7894

Vol. 4, No. 1, Desember 2021, 14 - 21

DOI: https://doi.org/10.31540/jpm.v4i1.1291

PENERBIT: LP4MK STKIP PGRI LUBUKLINGGAU
}

\title{
PENGOLAHAN SAMPAH ORGANIK RUMAH TANGGA MENJADI PUPUK ORGANIK DI KELURAHAN PONOROGO KOTA LUBUKLINGGAU
}

\author{
Zico Fakhrur Rozi ${ }^{1}$, Dian Samitra ${ }^{2}$, Harmoko ${ }^{3}$ \\ ${ }^{123}$ Program Studi Pendidikan Biologi, STKIP PGRI Lubuklinggau \\ Jalan Mayor Toha Kelurahan Air Kuti, Kota Lubuklinggau, 31628, Indonesia \\ Email: zico.fakhrurrozi@gmail.com
}

Setiap hari warga Kota Lubuklinggau memproduksi sampah rumah tangga sebanyak 158,2 ton. Konsep reuse, reduce, dan recycle masih menjadi cara terbaik dalam mengelola dan menangani sampah dengan berbagai permasalahan yang ada. Sampah rumah tangga terbagi menjadi 2 bagian menjadi sampah organik dan anorganik. Sampah organik merupakan sampah yang mudah membusuk seperti sisa makanan, sayuran, daun kering, yang masih bisa diolah dan dimanfaatkan. Sampah organik dapat diolah menjadi pupuk organik. Metode yang digunakan dalam pegabdian ini adalah ceramah, diskusi, demonstrasi dan praktek pengolahan sampah organik rumah tangga menjadi pupuk organik. Kegiatan ini mendapat sambutan yang sangat baik dari warga dan pihak Keluarahan Ponorogo Kota Lubuklinggau, karena setelah mengikuti kegiatan tersebut warga mendapat informasi dan mampu mengolah sampah organik rumah tangga untuk dijadikan pupuk organik. Selain itu kegiatan ini membatu pemerintah Kota Lubuklinggau mengatasi permasalahan sampah organik rumah tangga di Kelurahan Ponorogo Kota Lubuklinggau dan diharapkan menjadi percontohan bagi keluarahan yang lain.

ABSTRACK

Every day residents of Lubuklinggau City produce 158.2 tons of household waste. The concept of reuse, reduce, and recycle is still the best way to manage and handle waste with various existing problems. Household waste is divided into 2 parts into organic and inorganic waste. Organic waste is waste that easily decomposes such as food scraps, vegetables, dry leaves, which can still be processed and utilized. Organic waste can be processed into organic fertilizer. The methods used in this service are lectures, discussions, demonstrations and practices of processing household organic waste into organic fertilizer. This activity received a very good response from residents and the Ponorogo Village, Lubuklinggau City, because after participating in the activity, residents received information and were able to process household organic waste to be used as organic fertilizer. In addition, this activity helps the Lubuklinggau City government overcome the problem of household organic waste in Ponorogo Village, Lubuklinggau City and is expected to be a model for other families.

KEYWORDS

Sampah Organik, Pupuk Organik Cair

Organic Waste, Liquid Organic Fertilizer

\section{ARTICLE HISTORY}

Received 06 Juli 2021

Revised 11 Oktober 2021

Accepted 15 November 2021

CORRESPONDENCE Zico Fakhrur Rozi@ zico.fakhrurrozi@gmail.com 


\footnotetext{
JURNAL CEMERLANG: Pengabdian pada Masyarakat

P-ISSN 2654-4741 / E-ISSN 2655-7894

Vol. 4, No. 1, Desember 2021, $14-21$

DOI: https://doi.org/10.31540/jpm.v4i1.1291

PENERBIT: LP4MK STKIP PGRI LUBUKLINGGAU
}

\section{PENDAHULUAN}

Setiap kota memiliki permasalahan sampah yang ditimbulkan dari aktivitas rumah tangga begitu juga di Kota Lubuklinggau Provinsi Sumatera Selatan. Istilah 3R atau yang biasa disebut dengan reuse, reduce, dan recycle hingga kini masih menjadi cara terbaik dalam mengelola dan menangani sampah dengan berbagai permasalahannya yang ada. Penerapan sistem 3R menjadi salah satu solusi pengelolaan sampah yang dapat dilaksanakan oleh setiap orang dalam kegiatan sehari-harinya (Damayanti et al, 2020). Sampah organik merupakan sampah yang mudah membusuk seperti sisa makanan, sayuran, daun kering, yang masih bisa diolah dan dimanfaatkan. Sedangkan sampah anorganik merupakan sampah yang tidak mudah membusuk, seperti plastik wadah pembukus makanan, kertas, plastik, mainan, botol dan gelas minuman, kaleng dan kayu. Sampah anorganik dapat dijadikan sampah komersil. Pengelolaan sampah bertujuan untuk meningkatkan kesehatan masyarakat dan kualitas lingkungan serta menjadikan sampah sebagai sumberdaya. Dari sudut pandang kesehatan lingkungan, pengelolaan sampah dipandang baik jika sampah tersebut tidak menjadi media berkembang biaknya bibit penyakit serta sampah tersebut tidak menjadi medium perantara menyebarluasnya suatu penyakit. Sarat lainnya yang harus dipenuhi, yakni tidak mencemari udara, air dan tanah, tidak menimbulkan bau (tidak mengganggu nilai estetis), tidak menimbulkan kebakaran dan yang lainnya (Kusminah, 2018).

Berdasarkan Peraturan Pemerintah Nomor 27 Tahun 1999 Tentang Analisa Mengenai Dampak Lingkungan Hidup, yang pada dasarnya mendorong upaya kepada masyarakat bahwa betapa pentingnya lingkungan yang sehat, bersih dan indah demi mewujudkan pembangunan berkelanjutan yang berwawasan lingkungan sehat dalam rangka kelangsungan hidup masyarakat yang lebih baik dan terorganisir. Maka dengan peraturan tersebut masyarakat harus dapat menjadikan hal itu sebagai acuan untuk menjadikan daerah tempat tinggalnya 


\section{JURNAL CEMERLANG: Pengabdian pada Masyarakat \\ P-ISSN 2654-4741 / E-ISSN 2655-7894 \\ Vol. 4, No. 1, Desember 2021, $14-21$ \\ DOI: https://doi.org/10.31540/jpm.v4i1.1291 \\ PENERBIT: LP4MK STKIP PGRI LUBUKLINGGAU}

tergolong lingkungan yang bersih dan sehat. Kemudian di dalam Undang-Undang Republik Indonesia Nomor 18 Tahun 2008 Tentang Pengelolaan Sampah Pasal 12 Setiap orang dalam penge lolaan sampah rumah tangga dan sampah sejenis sampah rumah tangga wajib mengurangi dan menangani sampah dengan cara yang berwawasan lingkungan Pasal 19 Pengelolaan sampah rumah tangga dan sampah sejenis sampah rumah tangga.

Masyarakat di Kelurahan Ponorogo Kota Lubuklinggau belum memiliki cukup informasi dalam pengolahan sampah organik rumah tangga menjadi pupuk cair, sehingga sampah dibiarkan menumpuk pada saat menunggu truk pembuangan sampah untuk diangkut ke TPS. Hasil survey dan wawancara tim dengan mitra baik kepada masyarakat maupun dengan kelompok rumah tangga menjumpai permasalahan yang dihadapi antara lain yaitu, volume sampah yang menumpuk kadang berserakan di penampungan pada permukiman, tidak sedap baunya dan tidak enak dipandang mata serta mendatangkan vector penyakit. Tempat penampungan sampah sudah tidak sesuai lagi volumenya dengan sampah yang dikumpulkan warga sehingga jika pengangkutan tidak dilaksanakan tepat sesuai jadwal lingkungan menjadi kumuh. Sampah yang telah dipisahkan warga saat pengangkutan dicampur kembali sehingga pemilahan sampah yang dilakukan warga tidak memberikan manfaat. Tidak memiliki informasi tentang teknologi pengolahan sampah. Berdasarkan latar belakang di atas maka sangat baik jika masyarakat memiliki keterampilan dalam pengolahan sampah rumah tangga dan kemudian diolah menjadi pupuk organik di lingkungan masyarakat Kelurahan Ponorogo Kota Lubuklinggau.

\section{METODE}

Berdasarkan analisis masalah yang telah diuraikan, untuk membantu pemerintah Kota Lubuklinggau dalam mengatasi permasalahan sampah bisa dilakukan dengan melatih masyarakat agar mampu mengolah sampah rumah tangga menjadi produk yang bermanfaat bagi masyarakat. Sampah organik bisa 


\section{JURNAL CEMERLANG: Pengabdian pada Masyarakat \\ P-ISSN 2654-4741 / E-ISSN 2655-7894 \\ Vol. 4, No. 1, Desember 2021, $14-21$ \\ DOI: https://doi.org/10.31540/jpm.v4i1.1291 \\ PENERBIT: LP4MK STKIP PGRI LUBUKLINGGAU}

dimanfaatkan sebagai bahan baku dalam pembuatan pupuk organik. Untuk mencapai target dan luaran sesuai permasalahan yang dihadapi, digunakan beberapa metode, yang meliputi penyuluhan, transfer teknologi, demonstrasi dan pelatihan, praktek aplikasi teknologi, serta pendampingan dan monitoring. Tim pelaksana pengabdian kepada masyarakat (PKM) membagi kegiatan menjadi tahap persiapan dan pelatihan. Pada tahap persiapan dilakukan observasi ke lokasi dan koordinasi dengan mitra. Selanjutnnya, pada tahap pelatihan yaitu pemberian materi kepada masyarakat Kelurahan Ponorogo Kota Lubklinggau tentang pengelolaan sampah limbah rumah tangga. Dalam kegiatan ini digunakan bak komposter (drum) yang digunakan sebagai tempat untuk membuat pupuk organik dari sampah organik rumah tangga, dimana bahan baku yang digunakan pada kegiatan ini berasal dari sampah organik rumah tangga dengan bermacam-macam jenis sayuran. Pisahkan sampah organik (dapat terurai: sisa sayuran dan makanan, buah-buahan) dan non organik (tidak dapat terurai: botol,kaca,plastik). Potong sampah organik menjadi ukuran yang lebih kecil $\pm 1-2 \mathrm{~cm}$. Masukkan sampah organik yang telah dicacah ke dalam mini Komposter. Semprot sampah organik dengan larutan bio aktivator dengan ukuran 1 tutup botol /10 cc dicampur dengan 1 liter air sumur untuk 2 kali penyemprotan. Tutup mini komposter rapat-rapat Lakukan penyemprotan setiap kali memasukkan sampah. tutup rapat kembali. Diamkan kurang lebih 7- 14 hari agar terjadi proses komposting sehingga akan menghasilkan dua produk yaitu pupuk organik dan kompos (Nur, 2016). Ambil pupuk cair dengan membuka kran dimulai pada hari ke 7 dan seterusnya.

\section{HASIL dan PEMBAHASAN}

Kegiatan pengabdian ini telah dilaksanakan dengan menggunakan metode penyuluhan, transfer teknologi, demonstrasi dan pelatihan, praktek aplikasi teknologi, serta pendampingan dan monitoring. Pemberian materi oleh tim pengabdian pada masyarakat yaitu dosen dari Program Studi Pendidikan Biologi STKIP PGRI Lubuklinggau. Kegiatan pengabdian ini diikuti oleh masyarakat 


\section{JURNAL CEMERLANG: Pengabdian pada Masyarakat P-ISSN 2654-4741 / E-ISSN 2655-7894 \\ Vol. 4, No. 1, Desember 2021, $14-21$ \\ DOI: https://doi.org/10.31540/jpm.v4i1.1291 \\ PENERBIT: LP4MK STKIP PGRI LUBUKLINGGAU}

Kelurahan Ponorogo Kota Lubuklinggau yang berjumlah 15 peserta. Berdasarkan pengamatan pada saat penyampaian informasi dan demonstrasi ini nampak bahwa pengetahuan kelompok PKK tentang sampah terutama pengelolaan dan pengolahan sampah rumah tangga masih sangat minim. Berbagai pertanyaan diajukan secara antusias oleh para peserta dalam sesi tanya jawab. Secara garis besar inti dari pertanyaan para peserta adalah bagaimana cara memilah sampah rumah tangga secara benar. Sampah organik jika tidak dikelola dengan baik akan menimbulkan pencemaran lingkungan dan gangguan kesehatan bagi masyarakat sekitar. Hal ini dikarenakan limbah organik akan gampang membusuk sehingga dapat menimbulkan bau yang tidak sedap sehingga dapat menarik hewan kotor seperti kecoa dan tikus. Selain itu pembusukan sampah organik jika dibuang kesembarang tempat dapat menimbulkan pencemaran (Gresriantuti, Harahap, Herlina, \& Badrun, 2017). Hal tersebut dapat dikarenakan masyarakat belum memahami tentang pengolahan sampah organik lebih lanjut. Salah satu pemanfaatan sampah organik limbah rumah tangga adalah dengan membuat pupuk organik. Pupuk tersebut merupakan pupuk yang berasal dari sampah organik yang difermentasi dengan menggunakan komposter. Bahan dasar untuk membuat pupuk organik disekitar rumah jumlahnya melimpah, seperti sisa/sampah dapur, rumput/daun liar segar/kering dan sebagainya termasuk limbah pemotongan hewan dapat digunakan sebagai bahan pupuk organik/kompos, baik cair maupun padat.

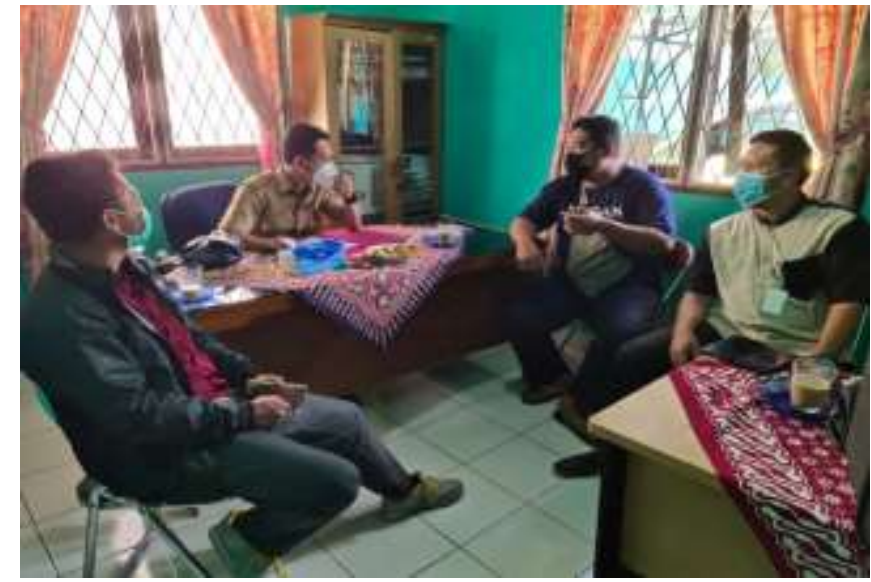

Gambar 1. Koordinasi Pelasksanaan Program 


\section{JURNAL CEMERLANG: Pengabdian pada Masyarakat P-ISSN 2654-4741 / E-ISSN 2655-7894 \\ Vol. 4, No. 1, Desember 2021, $14-21$ \\ DOI: https://doi.org/10.31540/jpm.v4i1.1291 \\ PENERBIT: LP4MK STKIP PGRI LUBUKLINGGAU}

Pada kegiatan ini peserta diberikan informasi tentang kriteria bahan/sampah rumah tangga yang bisa digunakan untuk pembuatan pupuk organik. Kriteria bahan yang digunakan diantaranya adalah sampah rumah tangga yang mudah busuk, mudah terurai dan mudah hacur. Pemilahan sampah dari warga menjadi sampah organik yaitu sampah yang dapat dikomposkan seperti sisa makanan, sisa ikan, sayur-sayuran, kulit buah dan lain-lain. Teknik pemotongan sampah organik juga harus diperhatikan, semakin kecil ukuran potongan bahan mentahnya, semakin cepat pula waktu pembusukannya. Ukuran bahan sekitar 1-2 cm sesuai untuk pengomposan ditinjau dari aspek sirkulasi udara yang mungkin terjadi. Pengelolaan sampah rumah tangga juga dapat dilakukan secara individu maupun kelompok masyarakat. Melalui pengelolaan sampah rumah tangga menjadi lebih bermanfaat dan membantu mengurangi volume sampah kota serta mengurangi beban pengelolaannya.

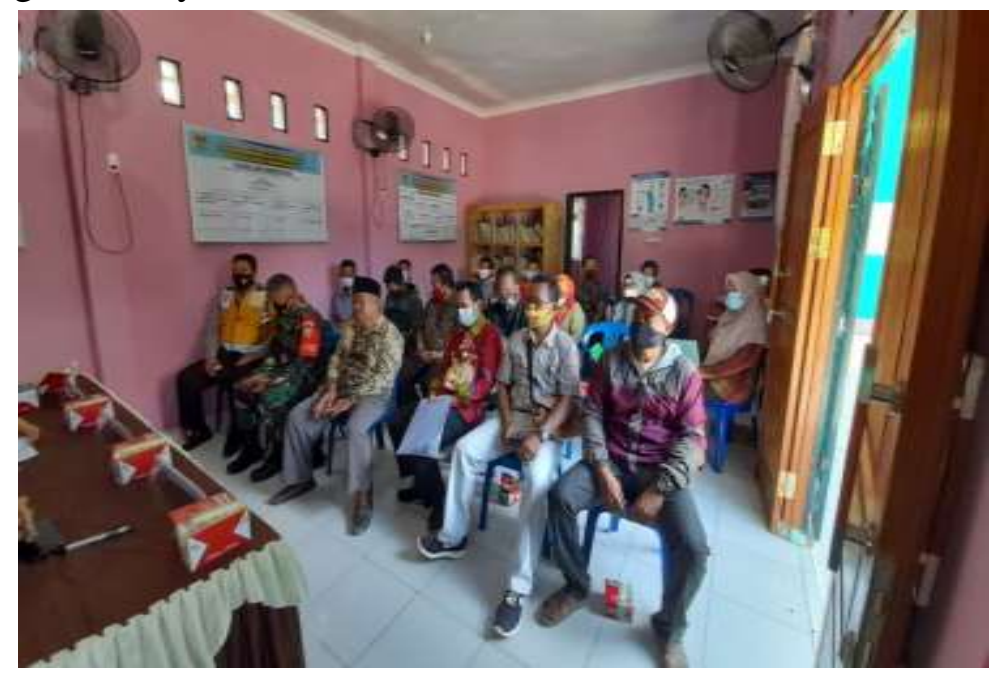

Gambar 2. Transfer teknologi pengolahan sampah organik.

Berbagai hasil penelitian mengindikasikan bahwa sebagian besar lahan pertanian intensif menurun produktivitasnya dan telah mengalami degradasi lahan, terutama terkait dengan sangat rendahnya kandungan karbon organik dalam tanah, yaitu 2\%. Padahal untuk memperoleh produktivitas optimal dibutuhkan karbon organik sekitar 2,5\%. Pupuk organik sangat bermanfaat bagi peningkatan produksi pertanian baik kualitas maupun kuantitas, mengurangi pencemaran lingkungan, 


\section{JURNAL CEMERLANG: Pengabdian pada Masyarakat \\ P-ISSN 2654-4741 / E-ISSN 2655-7894 \\ Vol. 4, No. 1, Desember 2021, $14-21$ \\ DOI: https://doi.org/10.31540/jpm.v4i1.1291 \\ PENERBIT: LP4MK STKIP PGRI LUBUKLINGGAU}

dan meningkatkan kualitas lahan secara berkelanjutan. Penggunaan pupuk organik dalam jangka panjang dapat meningkatkan produktivitas lahan dan dapat mencegah degradasi lahan. Sumber bahan untuk pupuk organik sangat beranekaragam, dengan karakteristik fisik dan kandungan kimia yang sangat beragam sehingga pengaruh dari penggunaan pupuk organik terhadap lahan dan tanaman dapat bervariasi. Selain itu, peranannya cukup besar terhadap perbaikan sifat fisika, kimia biologi tanah serta lingkungan. Pupuk organik yang ditambahkan ke dalam tanah akan mengalami beberapa kali fase perombakan oleh mikroorganisme tanah untuk menjadi humus. Bahan organik juga berperan sebagai sumber energi dan makanan mikroba tanah sehingga dapat meningkatkan aktivitas mikroba tersebut dalam penyediaan hara tanaman.

\section{SIMPULAN}

Kegiatan Pengabdian pada masayarakat ini bertujuan untuk memberikan informasi kepada masyarakat kelurahan Ponorogo Kota Lubuklinggau tentang pengolahan sampah organik rumah tangga sebagai bahan pembuatan pupuk organik cair. Setelah kegiatan masyarakat memiliki informasi tentang cara pengolahan sampah organik rumah tangga menjadi pupuk cair organik dan masyarakat dapat mengimplementasikan. Selain itu kegiatan ini diharapkan dapat membantu pemerintah Kota Lubuklinggau dalam menanggulangi sampah.

\section{DAFTAR PUSTAKA}

Damayanti R A., Adisurya S I., Dewanti A R., Nanda S. (2020). Pelatihan Pemanfaatan Kembali (Reuse) Sampah Anorganik Untuk Pelengkap Desain Interior Di Lahan Sempit, Kelurahan Kalianyar. Jurnal Abdi Masyarakat Indonesia Volume 2 No. 1.

Gesriantuti, N., Elsie, E., Harahap, I., Herlina, N., \& Badrun, Y. (2017). Pemanfaatan Limbah Organik Rumah Tangga dalam Pembuatan Pupuk Bokashi di Kelurahan Tuah Karya, Kecamatan Tampan, Pekanbaru. Jurnal Pengabdian UntukMu NegeRI, 1(1), 72-77.

Marliani N. (2014). Pemanfaatan Limbah Rumah Tangga (Sampah Anorganik) 


\section{JURNAL CEMERLANG: Pengabdian pada Masyarakat}

P-ISSN 2654-4741 / E-ISSN 2655-7894

Vol. 4, No. 1, Desember 2021, $14-21$

DOI: https://doi.org/10.31540/jpm.v4i1.1291

PENERBIT: LP4MK STKIP PGRI LUBUKLINGGAU

Sebagai Bentuk Implementasi Dari Pendidikan Lingkungan Hidup. Jurnal formatif 4(2): 124-132.

Nur Thoyib, Noor Ahmad R, Elma Muthia. (2016). Pembuatan Pupuk Organik Cair Dari Sampah Organik Rumah Tangga Dengan Penambahan Bioaktivator Em4 (Effective Microorganisms). Jurnal Konversi, Volume 5 No. 2.

Kusminah, I. L. 2018. Penyuluhan 4R (Reduce, Reuse, Recycle, Replace) dan Kegunaan Bank Sampah sebagai Langkah Menciptakan Lingkungan yang Bersih dan Ekonomis di Desa Mojowuku Kabupaten Gresik. Jurnal Pengabdian Masyarakat LPPM Untag Surabaya, 3(1): 22-28.

Siregar A H., Ginting S., Mardhiyya A. 2018. Pengelolaan Sampah Rumah Tangga Menjadi Pupuk Organik Menggunakan Komposter. Prosiding Seminar Nasional Penelitian \& Pengabdian pada Masyarakat ISBN: 978602-61545-0-7. 